\title{
The Effects of Mothers' Overprotection on Adolescents' Depressive Symptoms: The Mediating Effects of Adolescents' Basic Psychological Needs
}

\author{
Mi Young Baek, So Yean Lee \\ Department of Child Welfare and Studies, Sookmyung University, Seoul, Korea \\ 모의 과보호가 중학생 자녀의 우울증상에 미치는 영향: \\ 기본심리욕구의 매개효과 \\ 백미영, 이소연 \\ 숙명여자대학교 아동복지학과
}

\begin{abstract}
Objective: This study aimed to examine the mediating effects of male and female adolescents' basic psychological needs (i.e., autonomy, competence, and relatedness) in the relationship between mothers' overprotection and adolescents' depressive symptoms.

Methods: The participants included 292 middle school students (52.7\% girls) living in Gyeonggi. Correlation analysis, $t$-test, and PROCESS macro by Hayes (2013) were performed using the SPSS 22.0 software.

Results: Adolescents' autonomy and relatedness showed a significant mediating role between mothers' overprotection and depressive symptoms in all adolescents. In the case of male adolescents, only autonomy showed a significant mediating effect between mothers' overprotection and depressive symptoms.

Conclusion: Both mothers overprotection and adolescents' autonomy and relatedness should be considered to understand the development of depressive symptoms. The result also indicated that gender is an important factor when understanding the mediating role of basic psychological needs between mothers' overprotection and adolescents' depressive symptoms.
\end{abstract}

Keywords: mothers' overprotection, adolescents' depressive symptoms, basic psychological needs

\begin{abstract}
서론
청소년기는 아동기에서 성인기로 나아가는 과도기로써 급격 한 신체·심리 · 사회적 변화를 맞이하고 그 변화에 적응해 나 가는 시기이며, 이러한 적응과정에서 다양한 심리적인 문제 에 노출될 수 있다. 특히 청소년기는 우울증상이 빈번하게 발

Corresponding Author: So Yean Lee, Department of Child Welfare and Studies, Sookmyung Women's University, 100, Cheongpa-ro 47-gil, Yongsan-gu, Seoul, Korea

E-mail: leesy@sm.ac.kr
\end{abstract}

생하는 시기로 제시되어 왔다. 선행연구에서도 아동기에서 청 소년기로의 전이기에 우울증상이 증가하는 양상이 실증적으 로 확인되었고(Wickrama, Conger, \& Abraham, 2008), 이러한 양상은 우리나라 청소년을 대상으로 한 연구에서도 보고되었 다(Suh, 2011). 이는 사춘기의 호르몬 변화와 스트레스 사건의 증가, 그리고 이에 대한 청소년의 비효과적인 대처로 인해 우

(C)The Korean Association of Child Studies

This is an Open Access article distributed under the terms of the Creative Commons Attribution Non-Commercial License (http:// creativecommons.org/licenses/by-nc/4.0) which permits unrestricted noncommercial use, distribution, and reproduction in any medium, provided the original work is properly cited. 
울증상에 대한 취약성이 증가하기 때문으로 유추된다(Abela $\&$ Hankin, 2008). 이에 청소년은 우울증상과 같은 심리적인 부적응을 겪을 가능성이 클 수 있음이 시사된다.

실제로 청소년 건강행태 온라인 조사 통계 결과에 따르 면, 최근 1 년 동안 2 주 내내 일상생활을 중단할 정도의 슬픔 이나 절망감을 느꼈다고 보고하는 청소년이 중학생 $21.5 \%$, 고등학생 25.6\%로 나타났다(Centers for Disease Control and Prevention, 2015). 이러한 통계결과를 확인해보면 고등학생이 중학생보다 비교적 높은 우울증상의 비율을 보이고 있지만, 중 학생은 고등학생으로 접어드는 전 단계로 우울증상에 조기에 개입하고 대응하여 우울증상을 효과적으로 예방할 수 있는 시 기이기 때문에 중요하다. 더욱이 우울함을 느끼는 감정은 사춘 기를 전후해서 급격히 증가하기 때문에(Kwak \& Mun, 1993), 사춘기를 시작하거나 겪게 되는 중학생 시기에 우울증상이 발 현될 가능성이 크다. 더욱이 이러한 청소년기 우울증상은 성인 과 달리 우울감정이 감추어진 형태로 나타나기 때문에 증상이 표면적으로 뚜렷하게 드러나지 않을 수 있어 조기 발견이 어렵 고 방치될 우려가 많으며, 매사에 부정적이거나 반항적인 행동 과 무단결석, 가출, 성적 저하 등으로 위장되어 나타나고, 더 나 아가 학습장애, 비행, 약물남용, 자살 등의 문제를 초래할 수 있 다(Hauenstein, 2003; Korean Neuropsychiatric Association, 1998). 따라서 중학생의 전반적인 성장과 발달에 부정적인 영향을 미 칠 수 있는 우울증상에 대한 예방 및 치료적 개입을 모색하기 위해서는 우울증상에 대한 원인을 탐색할 필요가 있다.

청소년의 우울증상에 미치는 다양한 요인 중에서도 심리 사회적 환경인 부모양육행동은 중요한 위험요인 중 하나일 뿐 아니라(Alloy et al., 2001), 개인의 기질 특성 및 성격발달에 주요한 영향을 미치는 요인으로 고려되어 왔다(B. K. Kim \& Min, 2006). 실제 다수의 선행연구에서도 부모의 양육행동이 중학생 자녀의 우울증상에 부정적 영향을 미치는 요인이라는 것이 규명되었다(E. J. Kim, 2010; J. Jung \& Kim, 2011; Moon $\& \mathrm{Oh}, 2002)$. 이러한 부모의 양육행동 중에서도 특히 부모의 과보호가 자녀에게 미치는 영향에 대한 관심이 높아지고 있 다. 이는 우리사회의 출산율 저하가 자녀수 감소로 이어지면 서 부모의 기대나 관심이 점차적으로 그리고 과도할만큼 증가 하고 있기 때문이다(Ki \& Kim, 2014). 또한 우리나라 양육문화 의 특성상 부모가 자녀를 자신과 동일시하거나 자신의 소유물 로 간주하고, 자녀의 성취를 통해 대리만족하는 경향으로 인 해 자녀를 과보호하며 양육하게 될 가능성이 높다(Seong, Oh, Choi, \& Joo, 2013). 더욱이 한국사회의 지나친 입시경쟁이나 교육열은 부모의 과보호적 양육태도를 조장하는데 기여하고
있다. 이러한 부모의 과보호는 다른 발달 단계보다 청소년기 에 더욱 부정적인 영향을 미칠 수 있는데, 청소년기는 아동에 서 성인으로 변화하는 과도기로 하나의 독립된 개체로 성장할 준비를 하고, 신체·인지·심리적 특성의 많은 부분들이 성장하 는 시기이며, 부모에게 의존하려는 욕구와 독립하려는 욕구가 동시에 나타나는 시기이기 때문이다(Yoon \& Kang, 2011).

이러한 부모의 과보호는 자녀의 부정적 자동적사고 및 분 노(Suk \& Oh, 2014), 불안 및 공격성(Chun \& Han, 2013), 스 마트폰 중독(B. N. Kim \& Choi, 2013), 정서조절 및 또래관계 (S. Kim \& Chung, 2011)와 같은 다양한 요인에 부정적 영향을 미치는 것으로 규명되었다. 이 중에서도 부모의 과보호는 자 녀의 내재화 문제(Parker, Tupling, \& Brown, 1979), 그 중에서 도 특히 우울증상에 영향을 미치는 변인으로 보고되었다(H. Y. Kim, 2000; Moon \& Oh, 2002). 이는 청소년기의 특성상 자 녀가 스스로 하려는 경향이 강한데 부모가 과보호적 양육을 하게 되면 자녀와 마찰을 유발해서 무력감 및 좌절감, 더 나 아가 자녀의 우울증상을 높이는 것으로 유추된다(Ahn \& Mo, 2012).

부모의 과보호와 자녀의 우울증상간의 관계를 검증한 일 부 선행연구에서는 아버지와 어머니를 구분하여 검증하였다. 그 결과 아버지의 과보호보다 어머니의 과보호가 중학생 자 녀의 우울증상에 더욱 영향력 있는 요인으로 제시되었고 $(\mathrm{H}$. Y. Kim, 2000), 대학생을 대상으로 한 연구에서는 어머니의 과 보호만이 유의한 정적상관을 나타내(Herbert, McCormack, \& Callahan, 2010; Oh, 1998) 자녀의 우울증상에 어머니의 과보 호가 더 큰 영향을 미치는 요인이라는 것을 유추할 수 있다.

어머니의 과보호는 중학생 자녀의 기본심리욕구에도 영향 을 미치는 요인으로 제시되는데, 기본심리욕구는 자율성, 유 능감, 관계성 세 가지 요소로 구성된다. 자율성은 행동의 주체 로써 행동의 조절자이기를 바라며 결정에 대한 자유를 원하 는 욕구이고, 유능감은 자신이 유능하거나 효율적이라고 느끼 는 욕구이며, 관계성은 타인과 관계를 맺고자 하는 욕구이다 (Deci \& Ryan, 1985). 어머니의 과보호와 중학생 자녀의 기본 심리욕구와의 관계를 검증한 선행연구를 구체적으로 살펴보 면, 중학생 자녀가 어머니의 과보호를 높게 지각할수록 자율 성이 낮고(Chun, 2012), 대인관계에도 부정적인 영향을 미쳤 고(Jeong \& Oh, 2016), 초기 청소년기에 접어드는 초등학교 고 학년 자녀에게도 열등감을 갖게하며 자기유능감에도 부정적 인 영향을 미쳤다(S. Lee \& Choi, 2006). 이러한 결과를 종합하 면 어머니의 과보호가 중학생 자녀의 기본심리욕구인 자율성, 유능감, 관계성 모두에 부정적인 영향을 미치는 예측변인임을 
확인할 수 있다.

한편 기본심리욕구는 우울증상에도 영향을 미치는 데 자 녀의 자율적인 의사결정능력의 발달을 저해하는 것이 우울 에 영향을 미치고(Holmbeck et al., 2002), 낮은 자율성이 우울 증상에 영향을 주는 것으로 나타났다(Ma \& Son, 2012). 또한 유능감은 미래의 우울증상을 예측하는 변인이며(Veronneau, Koestner, \& Abela, 2005), 청소년이 자신의 능력이 결여되었 다고 지각하는 것은 우울증상과 부적상관을 보였다(Yi \& Lee, 2009). 뿐만 아니라 낮은 수준의 또래지지(Choi \& Kim, 2015) 와 부모지지(Ha, 2004), 대인관계(Jeong \& Oh, 2016)도 우울증 상에 영향을 미치는 것으로 보고되었다. 따라서 기본심리욕구 의 각 하위요인인 자율성, 유능감, 관계성은 우울증상에 영향 을 미치는 변인일 것으로 예측된다.

이상의 연구들을 종합하면 어머니의 높은 과보호는 중학 생 자녀의 자율성, 유능감, 관계성 욕구를 낮추고, 낮은 자율 성, 유능감, 관계성 욕구는 다시 우울증상을 증가시킬 것으로 예측된다. 즉, 모의 과보호와 중학생 자녀의 우울증상과의 관 계를 청소년의 기본심리욕구가 매개할 것으로 보인다. 이러한 매개모형에 대한 이론적 근거를 살펴보면, 가장 기본적인 사 회적 환경인 가정이 기본심리욕구를 가장 잘 충족시켜며, 이 러한 부모의 양육방식은 자녀의 내적동기와 내면화 과정의 발 달에 중요하다(Joussemet, Landry, \& Koestner, 2008). 그러나 부 모의 통제적 양육으로 인해 자녀의 자율성을 억압당하면 내적 동기와 내면화과정을 발달시키지 못해 결국 부적응적 양상을 나타내게 된다(H. Lee, 2013). 더욱이 자율성 욕구 충족은 다른 두 가지 욕구 충족에 영향을 주기 때문에(Deci et al., 2006) 이 러한 통제적인 부모양육은 기본심리욕구 세 가지 욕구 충족에 부정적인 영향을 주고, 이로 인해 내면화과정의 잘 발달되지 않으면 우울과 같은 심리적 부적응을 유발할 수 있다.

하지만 기존의 선행연구 중 세 변인의 관계를 통합적으로 검증한 연구는 전무하고, 유사한 연구가 있다고 하더라도 기 본심리욕구의 세 가지 하위요인을 통합적으로 살펴보지 않고 관련 변인간의 단편적인 관계만을 검증하였다는 제한점이 제 기된다. 더욱이 과보호 요인과 우울증상간의 관계를 검증한 연구에서는 두 변인의 관련성이 일관되지 않게 나타났는데(B.

K. Kim \& Min, 2006), 이는 중학생 자녀의 우울증상을 유발하 는 원인이 부모의 양육적인 측면 한 가지로만 설명할 수 없음 을 시사한다. 실제로 일부 선행연구에서는 부모양육 변인 이 외에도 청소년의 성격소질, 자아정체감과 같은 청소년의 개인 내적 변인을 통해 우울증상이 유발될 수 있음을 밝혔다(H. Y. Lee \& Ha, 2015; M. S. Park \& Ha, 2011). 이는 부모양육이라는
환경적 요인뿐만 아니라 청소년의 개인내적 변인을 함께 고려 해야할 필요성을 제기한다. 더욱이 기본심리욕구 하위요인인 자율성, 유능감, 관계성은 유기적으로 연결되면서도 서로 구 별되는 특성을 지니고 있으므로 세 가지 하위요인들의 매개경 로가 각각 다른 양상으로 나타날 수 있다.

더욱이 어머니의 과보호가 우울증상에 미치는 경로를 살펴 보면 자녀 성별에 따른 차이가 나타났다. 선행연구에서는 여 학생보다 남학생이 어머니의 양육태도 중 과잉기대를 더 높 게 지각하고(J. Jung \& Kim, 2011), 과보호는 남자의 경우와 달리 여자의 경우 유의한 영향을 미치지 않았고(Moon \& Oh, 2002), 남자의 경우 부모의 과보호가 우울에 유의한 영향을 미 쳤지만, 여자의 경우에는 방임만이 우울, 불안에 유의한 영향 력이 나타났다(Do, 2008). 또한 남자는 어머니의 '의존성을 조 장하는 과보호'가 관계지향성을 매개하여 우울에 영향을 주었 고, 여자는 어머니의 '통제적 과보호'가 성취지향성을 매개하 여 우울로 가는 경로가 유의하여 자녀의 성별에 따라 매개경 로도 다르게 나타났다(Oh, 1998). 이러한 원인을 추론해보면, 첫 번째는 남녀의 발달적 차이에서 기인할 수 있다. 일반적으 로 남아에 비해 여아가 사춘기에 빠르게 진입하며, 이로 인해 감수성 및 예민함이 증가하여 심리적으로 부정적 정서를 빈 번하게 느껴 우울증에 노출될 위험이 높다. 실제로 청소년기 로 진행하면서 여자가 남자에 비해 우울증상이 뚜렷하게 증 가하는 경향이 있다고 보고되었다(Kovacs, 1996). 또한 청소년 의 성별에 따라 인지적 차이도 나타나는데, 여성이 우울과 같 은 부정적 정서를 경험할 때 자신의 신체감각을 남성에 비해 더욱 과장하고 심각하게 지각하는 경향이 있으며(H.-Y. Jung, Park, \& Lee, 2004; Shin, 2000), 불쾌한 경험시 남성에 비해 여 성이 더 많은 반추를 사용하고 효율적으로 문제를 해결하지 못해 우울증에 더 취약하였다(Nolen-Hoesema \& Davis, 1999). 이렇듯 위의 선행연구에서는 여아의 특성이 남아보다 우울증 에 취약할 수 있다는 것을 보여준다. 그러나 다른 선행연구에 서는 여자보다 남자가 부모양육태도를 더 거부적이고 제재적 이라고 지각하는 경향이 나타났다. 이러한 원인은 여아보다 남아가 더 활동적이고 공격적인 특성을 지녀 부모로부터 더 통제적이고, 제재적인 양육을 받으며, 그것을 더욱 강하고 부 정적으로 지각할 수 있기 때문으로 유추하고 있다(Ro \& Shim, 2004). 이러한 연구결과를 종합했을 때 남아와 여아는 발달적, 기질적 특성이 차이로 인하여 겪는 심리적 경로가 다양할 것 으로 유추된다. 이에 어머니의 과보호가 중학생 자녀의 우울 증상에 미치는 영향에서도 성별에 따라 기본심리욕구의 매개 경로가 차이가 있을 것으로 예상됨에 따라 이를 탐색해볼 필 
요성이 제기된다.

따라서 본 연구에서는 어머니의 과보호와 중학생의 우울증 상에 미치는 영향에서 자율성, 유능감, 관계성이 어떤 역할을 하는지 검증하고, 이 경로가 성별에 따라 차이가 있는지를 추 가적으로 탐색하고자 한다. 본 연구를 통해 도출된 결과는 우 선 발달단계상 부모의 양육에서 벗어나 독립하는 단계에 있는 중학생의 우울증상을 이해할 수 있는 사회환경적 변인과 개인 내적 변인 그리고 그 변인간의 관계를 구체적이고 종합적인 경로로 파악할 수 있다는 점에서 의의가 있다. 특히 본 연구는 기본심리욕구 하위요인에 따른 각각의 경로를 파악함으로써 어머니의 과보호로 중학생의 어떤 기본심리욕구가 좌절되어 우울증상이 발현되는지를 구체적으로 파악할 것으로 기대된 다. 또한 청소년의 성별에 따라 자율성, 유능감, 관계성의 매개 역할이 다르게 나타난다면 청소년의 성별에 따라 우울증상을 감소시키기 위해 어떤 기본심리욕구에 집중해야 하는지에 대 해 차별적으로 접근할 필요성을 제기할 수 있을 것이다. 구체 적인 연구문제는 다음과 같다.

\section{연구문제 1}

중학생 자녀가 지각한 모의 과보호가 우울증상에 미치는 영 향에서 기본심리욕구의 하위요인의 매개효과는 어떠한가?

\section{연구문제 2}

중학생 자녀가 지각한 모의 과보호가 우울증상에 미치는 영 향에서 기본심리욕구의 하위요인의 매개효과는 성별에 따라 어떠한가?

\section{연구방법}

\section{연구대상}

본 연구에서는 청소년 중 중학생을 연구대상으로 선정하였다. 그 이유는 사춘기를 전후해서 우울감이 급격하게 증가하며 (Kwak \& Mun, 1993), 이러한 사춘기를 겪는 주 대상층이 중학 생 시기로 우울증상이 발현되기 시작함에 따라 적극적인 개입 이 요구되는 시기라고 판단했기 때문이다. 본 연구의 자료수 집을 위해 경기지역에 소재한 중학교 2곳에 재학 중인 중학생 400 명에게 질문지를 배부하였다. 이 중 347부가 회수되었고, 회수된 질문지 중 응답된 문항이 $90 \%$ 이상 누락되거나 부모 동의가 누락된 55 부를 제외하고 최종적으로 292 명의 자료를
대상으로 분석을 실시하였다. 연구 대상자의 남녀 성별분포는 남학생이 138 명(47.3\%), 여학생이 154 명(52.7\%)이었고, 학년 분포는 1학년 94명(32.2\%), 2학년 106명(36.3\%), 3학년 92명 (31.2\%)로 나타났다.

\section{연구도구}

\section{모의 과보호 척도}

모의 과보호를 측정하기 위해 Chung (2008)이 개발하고 타당 화한 '청소년이 지각한 어머니의 과보호 척도'를 사용하였다. 이 척도는 청소년 대상으로 개발된 자기보고식 검사로 하위요 인으로는 과잉교육열로 인한 지나친 기대를 나타내는 '과잉기 대', 지나친 간섭으로 혼자 할 수 있는 기회를 박탈하는 '자율 성 저해', 자녀에게 지나치게 밀착하여 엄격한 통제와 관리를 하는 '과잉통제', 자신의 불안을 자녀에게 투사하여 자녀를 지 나치게 보호하는 '과잉보호 및 불안', 자녀에 대한 과잉애착으 로 인해 지나친 접촉과 과잉 애정을 나타내는 '과잉애정'의 5 가지 하위요인으로 구성되어 있다. 각 하위요인은 5 문항씩 총 25 문항으로 구성되어 있고 각 문항에 대해 4점 리커트 척도 (전혀 그렇지 않다[1] 매우그렇다[4])로 응답하도록 되어있 으며 점수가 높을수록 과보호 경향이 높은 것으로 해석한다. 본 연구에서는 과보호 5 가지 하위요인을 통합한 총점을 사용 하였고, 모의 과보호 척도의 내적합치도(Cronbach's $\alpha$ )는 .87 로 나타났다.

\section{기본심리욕구 척도}

기본심리욕구를 측정하기 위해 Ryan과 Deci가 2002년에 개 발한 기본심리욕구 척도(Basic Psychological Need Scale)를 M. H. Lee와 Kim (2008)이 청소년을 대상으로 타당화한 '한국형 기본심리욕구 척도'를 사용하였다. 이 척도는 개인의 자율성 (autonomy), 유능감(competence), 관계성(relatedness)의 3가지 하위요인으로 구성되며, 각 요인의 점수가 높을수록 기본심리 욕구가 만족함을 의미한다. 이 척도는 각 하위요인별로 6 문항 씩 총 18 문항으로 구성되어 있으며, 각 문항의 응답방식은 5 점 리커트 척도(전혀 아니다[1] 매우 그렇다[5])이다. 본 연구 에서 산출된 기본심리욕구 척도의 내적합치도(Cronbach's $\alpha$ ) 는 .89 이었고, 각 하위요인별 신뢰도는 자율성 .74 , 유능감 .87 , 관계성 .84 이었다. 본 연구에서는 기본심리욕구의 각 하위요 인별 총점을 사용하였다. 
Table 1

Descriptive Statics and Gender Differences for the Variable

\begin{tabular}{lccc}
\hline & \multicolumn{1}{c}{$\begin{array}{c}\text { Male } \\
\text { Variables }\end{array}$} & \multicolumn{1}{c}{$\begin{array}{c}\text { Female } \\
(n=138)\end{array}$} & \multicolumn{1}{c}{$M(S D)$} \\
\cline { 2 - 4 } \multicolumn{1}{c}{ Mothers' overprotection } & $1.88(.40)$ & $1.77(.35)$ & 2.44 \\
Autonomy & $3.80(.64)$ & $3.85(.65)$ & -0.65 \\
Competence & $3.46(.72)$ & $3.52(.77)$ & -0.77 \\
Relatedness & $3.75(.64)$ & $3.88(.67)$ & -1.70 \\
Depressive symptoms & $1.45(.27)$ & $1.46(.30)$ & -0.46 \\
\hline
\end{tabular}

Note. $N=292$.

\section{우울증상 척도}

우울증상을 측정하기 위해 Kovacs (1985)가 개발한 Children's Depression Inventory (CDI)를 Cho와 Lee (1990)가 아동. 청소년 의 연령에 맞게 번안하고 국내표준화 한 한국어판 소아우울척 도를 사용하였다. 이 척도는 7세 17세 아동과 청소년에게 실 시할 수 있는 자기보고형 척도로 총 27문항으로 구성되어 있 다. 각 문항은 우울감의 심각도에 따라 0-2점까지 채점되며, 총점의 범위는 0-54점으로 점수가 높을수록 우울정도가 심각 한 것을 의미한다. 본 연구에서 산출된 우울증상 척도의 내적 합치도(Cronbach's $\alpha)$ 는 .87이었다.

\section{연구절차}

본 연구를 수행하기 위해 경기지역에 위치한 중학교 2곳을 직 접 방문하여 학교장 및 관계자들에게 연구의 취지 및 내용을 설명하여 협조를 구한 후 2016년 7월부터 8월까지 중학교 1-3 학년 학생 총 400 명을 대상으로 설문지를 배포하였다. 이 중 347 부가 회수되었으며, 응답이 $90 \%$ 이상 누락되거나 부모 동 의가 누락된 55부 제외하고, 292 부를 자료분석에 포함하였다. 자료수집과 모든 연구절차는 $S$ 대학교 생명윤리심의위원회의 승인을 받았다(IRB 승인번호 SMWU-1605-HR-020-02).

\section{자료분석}

본 연구는 모의 과보호와 중학생의 우울증상의 관계에서 성별 에 따른 기본심리욕구의 매개효과를 검증하기 위해 SPSS 22.0 (IBM Co., Armonk, NY)을 사용하였다. 우선 연구대상의 주요 변인들의 특성을 확인하기 위해 기술통계 분석을 실시하였고,
측정도구의 신뢰도 검증을 위해 Cronbach's $\alpha$ 계수를 산출하였 다. 그 후 변인들 간의 관계를 확인하기 위해 Pearson의 상관분 석을 실시하였고, 모의 과보호가 중학생의 우울증상에 미치는 영향에서 성별에 따른 기본심리욕구의 매개효과를 검증하기 위해 Hayes (2013)가 제안한 PROCESS macro프로그램을 사용 하여 분석을 실시하였다.

\section{연구결과}

\section{주요 변인의 기술통계 및 성별에 따른 평균차이 검증}

연구문제 분석에 앞서 주요 변수의 전반적인 경향을 알아보기 위해 기술통계 분석을 실시하였고, 청소년의 성별에 따른 변 수들의 평균차이를 검증하기 위하여 독립표본 $t$ 검정을 실시하 였다. Table 1 에서 확인할 수 있듯이 모든 변인들에서 유의한 성별 차이가 확인되지 않았다. 자료의 정규성 충족 여부를 판 단하기 위해 왜도, 첨도를 산출한 결과, 과보호 2번 문항을 제 외한 모든 문항에서 왜도의 절대값이 3 , 첨도의 절대값이 10 미만으로 나타나 정규성 가정을 충족하였다. 과보호 2번 문항 (“내가 이성친구를 만나러 갈 때 따라 오신다.”)은 이성친구가 있는 청소년에게만 해당되는 문항으로 보편적으로 관찰되기 어려운 문항이었기 때문에 이러한 결과가 나타난 것으로 유추 된다. 문항 제외시 과보호척도의 타당도가 확보되기 어려워 이 문항을 포함해 과보호 총점을 산출하였고, 과보호 총점의 왜도와 첨도값은 정규성 가정을 충족한 것을 확인하였다. 


\section{어머니의 과보호, 중학생 자녀의 우울증상, 기본심리욕구와의 상관관계}

주요 변인 간의 상관관계를 알아보기 위해 Pearson 상관분석을 실시한 결과, 독립변인인 모의 과보호는 종속변인인 중학생 자녀의 우울증상 $(r=.25, p<.01)$ 과 유의한 정적 상관관계를 그리고 매개변인인 기본심리욕구 하위요인인 자율성 $(r=-.39$, $p<.01)$, 관계성 $(r=-.14, p<.05)$ 과 유의한 부적 상관관계를 나 타냈다. 매개변인인 기본심리욕구의 자율성 $(r=-.50, p<.01)$, 유능감 $(r=-.39, p<.01)$, 관계성 $(r=-.47, p<.01)$ 과 종속변인인 우울증상은 부적 상관관계를 나타냈다. 그러나 모의 과보호와 유능감 $(r=-.03, p>.05)$ 과의 상관관계는 유의하지 않았다.

성별에 따른 주요 변인 간의 상관관계를 알아보기 위해 Pearson 상관분석을 추가적으로 실시한 결과는 Table 2 와 같다. 남자중학생의 경우, 독립변인인 모의 과보호가 종속변인인 우 울증상 $(r=.25, p<.01)$ 과 유의한 정적상관이 그리고 매개변인 인 기본심리욕구 하위요인 중 자율성 $(r=-.39, p<.01)$ 과만 유 의한 부적상관을 나타냈다. 남자중학생의 기본심리욕구 하위 요인인 자율성 $(r=-.51, p<.01)$, 유능감 $(r=-.36, p<.01)$, 관계성 $(r=-.48, p<.01)$ 은 우울증상과 유의한 부적상관이 나타났다.

여자중학생의 경우, 독립변인인 모의 과보호는 종속변인인 우울과는 유의하지 않은 상관을 $(r=.14, p>.05)$ 그리고 매개 변인인 여자중학생의 기본심리욕구 하위요인 자율성 $(r=-.37$, $p<.05)$, 관계성 $(r=-.21, p<.05)$ 만이 부적상관을 나타냈다. 매 개변인인 기본심리욕구의 자율성 $(r=-.49, p<.01)$, 유능감 $(r=$ -.41, $p<.01)$, 관계성 $(r=-.48, p<.01)$ 은 종속변인인 우울증상 과 유의한 부적상관을 나타냈다.

\section{모의 과보호와 중학생 자녀의 우울증상의 관계에서 기본심리욕구의 매개효과}

어머니의 과보호와 중학생 자녀의 우울증상의 관계에서 기본 심리욕구 하위요인의 매개효과를 검증하기 위해 Hayes (2013) 가 제안한 매개모형 분석을 실시하였다. 분석과정에서 부트 스트래핑(bootstrapping)으로 재추출된 표본 수는 5,000개였으 며, $95 \%$ 신뢰구간에서 구한 간접효과 계수의 하한값과 상한 값을 검토하여 0을 포함하는지 확인하였다(Shorout \& Bogler, 2002).

Table 2

Correlations Among the Variables by Gender

\begin{tabular}{|c|c|c|c|c|c|}
\hline Variables & 1 & 2 & 3 & 4 & 5 \\
\hline 1. Mothers' overprotection & - & $-.37^{* *}$ & -.05 & $-.21^{* *}$ & .14 \\
\hline 2. Autonomy & $-.40^{* *}$ & - & $.49^{* *}$ & $.52^{* *}$ & $-.49^{* *}$ \\
\hline 3. Competence & -.01 & $.22^{* *}$ & - & $.54^{* *}$ & $-.41^{* *}$ \\
\hline 4. Relatedness & -.04 & $.34^{* *}$ & $.62^{* *}$ & - & $-.48^{* *}$ \\
\hline 5. Depressive symptoms & $.25^{* *}$ & $-.51^{* *}$ & $-.36^{* *}$ & $-.48^{* *}$ & - \\
\hline
\end{tabular}

Note. Males below and females above the diagonal.

${ }^{* *} p<.01$.

Table 3

Mediating Effects of Basic Psychological Needs on the Relationship Between Mothers' Overprotection and Adolescents' Depressive Symptoms

\begin{tabular}{|c|c|c|c|c|c|c|c|c|}
\hline Independent variable & & Mediating variable & & Dependent variable & Indirect effect & $S E$ & \multicolumn{2}{|c|}{$95 \% \mathrm{CI}$} \\
\hline $\begin{array}{l}\text { Mothers' } \\
\text { overprotection }\end{array}$ & $\rightarrow$ & Autonomy & $\rightarrow$ & $\begin{array}{l}\text { Depressive } \\
\text { symptoms }\end{array}$ & .16 & .03 & .06 & .17 \\
\hline $\begin{array}{l}\text { Mothers' } \\
\text { overprotection }\end{array}$ & $\rightarrow$ & Competence & $\rightarrow$ & $\begin{array}{l}\text { Depressive } \\
\text { symptoms }\end{array}$ & .01 & .01 & -.01 & .03 \\
\hline
\end{tabular}

Note. $N=292$. 
분석결과, Table 3 에서 확인할 수 있듯이 과보호 $\rightarrow$ 자율성 $\rightarrow$ 우울증상, 과보호 $\rightarrow$ 관계성 $\rightarrow$ 우울증상의 두 경로에서만 매개 효과가 유의하였다. 즉 모의 높은 과보호를 받은 중학생은 자 율성 및 관계성이 낮고, 자율성과 관계성이 낮은 중학생일수 록 우울증상이 높음을 의미한다.

추가적으로 간접경로간의 유의미한 차이를 분석한 결과 과 보호 $\rightarrow$ 자율성 $\rightarrow$ 우울증상 경로와 과보호 $\rightarrow$ 관계성 $\rightarrow$ 우울증상 비교에서 신뢰구간 내에 0이 포함되지 않아 두 매개경로간 유 의미한 차이가 확인되었다. 즉, 자율성을 매개로 한 간접경로 계수가 관계성을 매개로 한 간접경로계수보다 유의미하게 컸 다. 이는 어머니의 과보호가 전체 중학생 자녀의 관계성보다 자율성에 더욱 큰 영향을 미쳐 우울증상을 높인다는 것을 의 미한다.

\section{모의 과보호와 중학생 자녀의 우울증상의 관 계에서 성별에 따른 기본심리욕구의 매개효과}

어머니의 과보호와 중학생 자녀의 우울증상의 관계에서 기본 심리욕구 하위요인의 매개효과가 청소년의 성별에 따라 다르 게 나타나는지를 확인하기 위해 위와 동일한 방법으로 검증하 였다.

Table 4에서 제시한 바와 같이 남자중학생의 경우 모의 과 보호 $\rightarrow$ 자율성 $\rightarrow$ 우울증상의 경로에서만 매개효과가 유의하 였다. 즉 모의 높은 과보호를 받은 남자중학생은 자율성이 낮 고, 자율성이 낮을수록 남자중학생의 우울증상이 높다는 것을 의미한다.

Table 5에서 확인할 수 있듯이, 여자중학생의 경우 과보호 $\rightarrow$ 자율성 $\rightarrow$ 우울증상, 과보호 $\rightarrow$ 관계성 $\rightarrow$ 우울증상의 두 경로

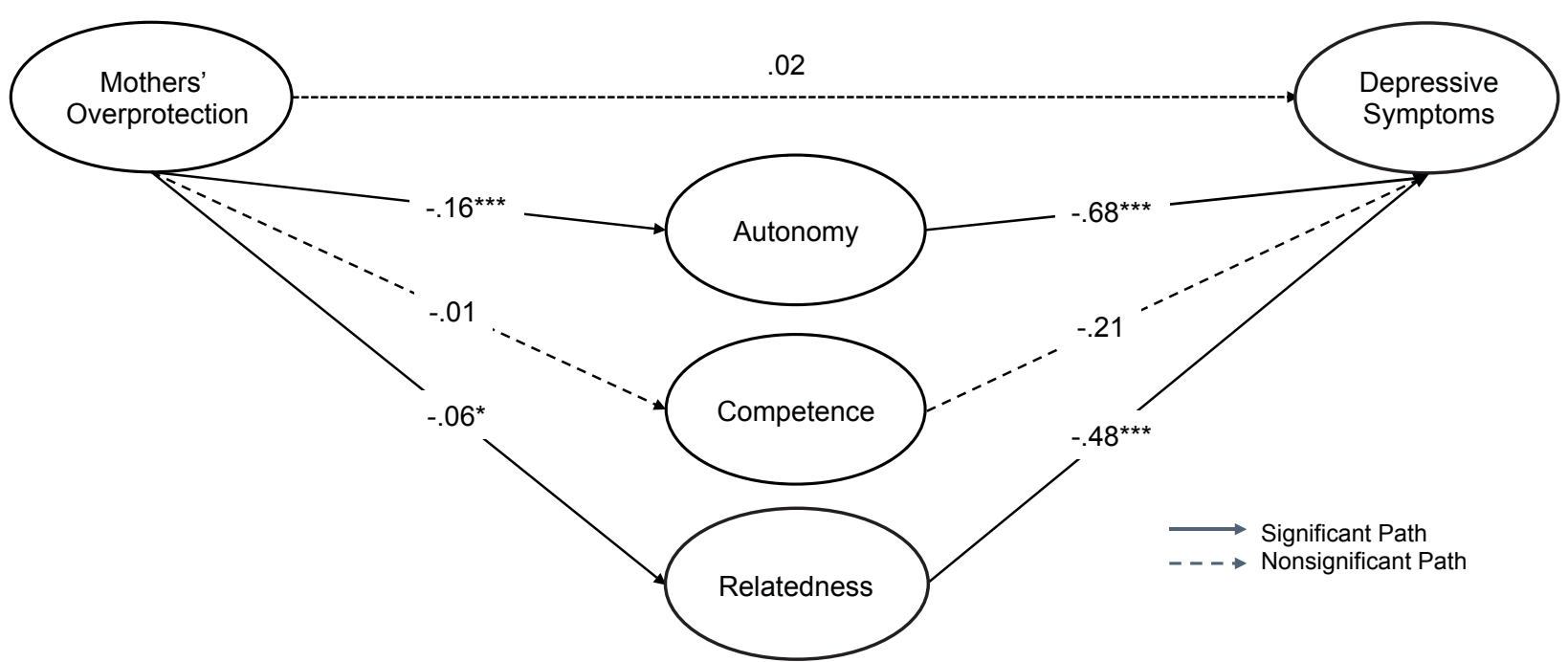

Figure 1. Adolescents' direct and indirect paths from mothers' overprotection to their depressive symptoms.

${ }^{*} p<.05 .{ }^{* * *} p<.001$.

Table 4

Mediating Effects of Basic Psychological Needs on the Relationship Between Mothers' Overprotection and Boys' Depressive Symptoms

\begin{tabular}{|c|c|c|c|c|c|c|c|c|}
\hline \multirow[b]{2}{*}{ Independent variable } & & \multirow[b]{2}{*}{ Mediating variable } & \multirow{2}{*}{\multicolumn{2}{|c|}{ Dependent variable }} & \multirow[b]{2}{*}{ Indirect effect } & \multirow[b]{2}{*}{$S E$} & \multicolumn{2}{|c|}{$95 \% \mathrm{CI}$} \\
\hline & & & & & & & Boot LLCI & Boot ULCI \\
\hline $\begin{array}{l}\text { Mothers' } \\
\text { overprotection }\end{array}$ & $\rightarrow$ & Autonomy & $\rightarrow$ & $\begin{array}{l}\text { Depressive } \\
\text { symptoms }\end{array}$ & .10 & .03 & .05 & .17 \\
\hline $\begin{array}{l}\text { Mothers' } \\
\text { overprotection }\end{array}$ & $\rightarrow$ & Competence & $\rightarrow$ & $\begin{array}{l}\text { Depressive } \\
\text { symptoms }\end{array}$ & -.01 & .01 & -.02 & .02 \\
\hline $\begin{array}{l}\text { Mothers' } \\
\text { overprotection }\end{array}$ & $\rightarrow$ & Relatedness & $\rightarrow$ & $\begin{array}{l}\text { Depressive } \\
\text { symptoms }\end{array}$ & .01 & .02 & -.03 & .05 \\
\hline
\end{tabular}

Note. $N=138$. 
Table 5

Mediating Effects of Basic Psychological Needs on the Relationship Between Mothers' Overprotection and Girls' Depressive Symptoms

\begin{tabular}{|c|c|c|c|c|c|c|c|c|}
\hline \multirow[b]{2}{*}{ Independent variable } & \multirow{2}{*}{\multicolumn{2}{|c|}{ Mediating variable }} & \multirow{2}{*}{\multicolumn{2}{|c|}{ Dependent variable }} & \multirow[b]{2}{*}{ Indirect effect } & \multirow[b]{2}{*}{$S E$} & \multicolumn{2}{|c|}{$95 \% \mathrm{CI}$} \\
\hline & & & & & & & Boot LLCI & Boot ULCI \\
\hline $\begin{array}{l}\text { Mothers' } \\
\text { overprotection }\end{array}$ & $\rightarrow$ & Autonomy & $\rightarrow$ & $\begin{array}{l}\text { Depressive } \\
\text { symptoms }\end{array}$ & .11 & .05 & .03 & .24 \\
\hline $\begin{array}{l}\text { Mothers' } \\
\text { overprotection }\end{array}$ & $\rightarrow$ & Competence & $\rightarrow$ & $\begin{array}{l}\text { Depressive } \\
\text { symptoms }\end{array}$ & .01 & .01 & -.01 & .05 \\
\hline $\begin{array}{l}\text { Mothers' } \\
\text { overprotection }\end{array}$ & $\rightarrow$ & Relatedness & $\rightarrow$ & $\begin{array}{l}\text { Depressive } \\
\text { symptoms }\end{array}$ & .05 & .04 & .01 & .15 \\
\hline
\end{tabular}

Note. $N=153$.
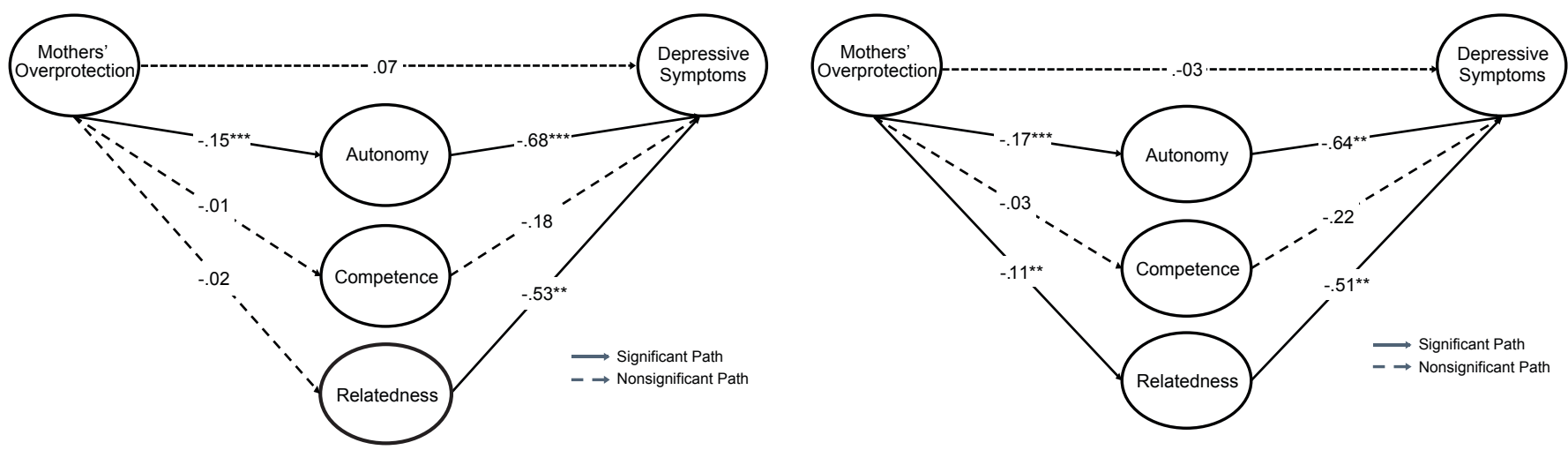

Figure 2. Direct and indirect paths from mothers' overprotection to adolescents' depressive symptoms by gender (Boys, left; Girls, right).

${ }^{* *} p<.01 .{ }^{* * *} p<.001$.

에서만 매개효과가 유의하였다. 즉 모의 높은 과보호를 받은 여자중학생은 자율성 및 관계성이 낮고, 자율성과 관계성이 낮을수록 여자중학생의 우울증상이 높다는 것을 의미한다.

\section{논의 및 결론}

본 연구는 어머니의 과보호가 중학생 자녀의 우울증상에 미치 는 영향에서 성차에 따른 기본심리욕구 하위요인의 매개효과 를 알아보고자 하였다. 연구의 주요한 결과를 중심으로 논의 하면 다음과 같다.

첫째, 부모 과보호에 따른 성별에 차이를 검증한 결과, 성별 에 따라 어머니의 과보호에 차이가 없는 것으로 나타났다. 이 는 여학생보다 남학생이 어머니의 양육태도 중 과잉기대를 더 높게 지각하며(J. Jung \& Kim, 2011), 부모로부터 더 많은 기대 와 간섭을 받는다고 제시한 연구결과(Sohn et al., 2001)와 불일 치하는 결과이다. 이러한 원인을 살펴보면, 위 선행연구에서
는 부모양육태도 하위요인으로서 과잉기대, 과잉간섭의 요인 으로 과보호가 포함되어있는 반면, 본 연구에서는 독립적인 과보호 척도로 자녀에 대한 과잉애착으로 인해 지나친 접촉과 애정을 나타내는 과잉애정 요인이 포함되어 있다는 데 큰 차 이점이 있었다. 실제로 선행연구에서는 애정에 기반한 과보호 는 여자가 남자보다 부정적인 영향을 덜 받는다고 주장하였다 (J. Kim \& Oh, 2011). 따라서 이러한 차이는 여학생의 경우 과 잉애정적 요소를 과보호로 받아들이지 않는 경향으로 인해 성 별에 따른 차이가 유의하지 않았을 것으로 유추된다.

둘째, 어머니의 과보호는 중학생 자녀의 우울증상과 유의 한 정적 상관관계를 나타냈다. 이는 어머니의 높은 과보호 경 향이 중학생의 높은 우울증상과 관련이 있음을 의미한다. 이 러한 연구결과는 어머니의 과보호가 자녀의 내재화문제 중 특 히 우울증상과 관련이 있고(H. Y. Kim, 2000), 과보호가 자녀 의 우울증상을 예측할 수 있는 변인으로 규명한 연구결과와 일치한다(B. K. Kim \& Min, 2006). 이처럼 어머니의 과보호를 받고 자란 청소년 자녀는 스스로 주변의 문제를 처리해 본 경 
험이 없어 발달단계에 적합한 과업들을 해결할 수 있는 능력 을 발달시키지 못한다(Wexberg, 1974). 이로 인해 인생에서 어 려운 상황에 직면했을 때 열등감에 빠지거나 부모에게 의존적 이게 될 수밖에 없는 상황에 반복되면서 무기력감을 느끼며 우울증상이 발현될 수 있을 것으로 유추된다.

또한, 어머니의 과보호는 중학생의 기본심리욕구 하위요인 인 자율성, 관계성과 유의한 부적상관이 있었으나, 유능감과 는 유의한 상관이 나타나지 않았다. 이는 어머니의 높은 수준 의 과보호가 중학생의 낮은 자율성, 관계성과 관련됨을 의미한 다. 이러한 결과는 청소년이 어머니의 과보호를 높게 지각할수 록 자율성이 낮으며(Chun, 2012), 과보호를 받은 자녀는 대인 관계와 사회화 문제를 야기할 수 있다는 연구결과를 지지한다 (Chung \& Chang, 2008; Jeoung, 2007). 이러한 원인을 구체적으 로 살펴보면, 청소년기의 중요한 발달과업은 자율성을 획득하 는 것으로 독립된 인격체로 성장하여 자신의 인생에 대한 주체 적인 책임을 갖고 자신의 삶을 스스로 결정하고 조절할 수 있 다는 신념을 형성하는 것이 중요하다(Chun, 2012). 하지만 어 머니의 과보호는 자녀의 자율적인 의사결정을 박탈하고 부모 가 자녀를 대신하여 의사결정함으로써 자녀가 자율성을 발휘 하는데 어려움을 겪을 수 있음을 유추할 수 있다. 또한 어머니 의 과보호는 청소년 자녀의 관계성을 좌절시킬 수도 있는데, 과보호를 받은 아동은 자기중심성이 강하여 타인을 배려하지 못해 관계에서 많은 좌절과 어려움을 겪게 될 수 있기 때문이 다(C.-K. Kim, 2000; A.-C. Park, 1998). 그러나 유능감은 어머니 의 과보호와 유의한 상관이 나타나지 않았는데, 이는 어머니 의 과보호와 아동기 자녀의 유능감이 유의한 부적상관이 있다 는 연구(Yi \& Lee, 2009)와 불일치하는 결과이다. 이는 아동을 대상으로 한 선행연구와 달리 본 연구대상이 청소년으로 연령 에 따라 유능감 발달에 미치는 영향이 상이하기 때문으로 유 추된다. 연령과 관련하여 유능감의 특성을 살펴보면, 청소년 이 초등학생보다 더 낮은 유능감을 가지는 것으로 확인되었는 데(Soenens \& Vansteenkiste, 2005; Trouiloud, Sarrazin, Bressoux, $\&$ Bois, 2006). 초등학교 시기에 비해 중학교에서는 교사와 일 대일 접촉이 줄어드는 것에 반해 학생들이 감당해야 할 학업량 은 급격하게 증가하고, 중학교 교사들은 학생들의 수행을 보 다 엄격하게 평가하며, 사회적 비교를 기반으로 한 기준을 사 용한다. 이로 인해 중학교 시기에 들어서면서 학생들의 성적하 락과 자기지각 및 동기저하에 영향을 미치는 것으로 나타났다 (Eccles et al., 1993). 이에 청소년 시기의 유능감은 부모의 양육 태도 보다는 학교에서 수행하는 학업능력이나 또래나 교사에 의한 평가 등이 더욱 영향을 줄 수 있을 것으로 유추된다.
또한 상관분석 결과 중학생의 기본심리욕구인 자율성, 유 능감, 관계성은 우울증상과 유의한 부적상관을 보였다. 이는 낮은 자율성, 유능감, 관계성의 수준은 높은 우울증상과 관련 된다는 것을 의미한다. 이러한 결과는 자율성, 유능감, 관계성 욕구가 우울증상을 예측하는 변인으로 규명된 연구를 지지한 다(Inguglia et al., 2016; S. S. Kim, 2015). 이처럼 청소년의 기본 심리욕구가 좌절되면 심리적으로 불안정하고 긴장하게 되는 데 이에 대한 대처반응으로 내부로 향하는 우울증상 등이 발 현될 수 있다(Averil, 1983). 구체적으로 자율성과 우울증상이 관련되는 이유를 발달적 관점에서 살펴보면 청소년기는 독립 해나가는 단계로 자율성이 중요한데, 이 시기에 자율성을 만 족시키지 못하면 다양한 상황에서의 대처능력과 기술이 부족 하여 좌절감과 무력감을 느껴 우울증상이 나타날 가능성이 있 다. 다음으로 청소년의 유능감과 우울증상이 관련되는 원인을 유추해보면, 유능감은 청소년 자신의 능력에 대한 지각으로 이러한 능력이 결여되었다고 지각할 경우 도전적인 상황에 부 딪혔을 때 문제를 잘 해결해 나갈 수 없으며, 그로 인해 좌절감 과 무력감을 경험하게 되어 우울증상을 유발시킬 가능성이 있 다(Yi \& Lee, 2009). 마지막으로 청소년의 관계성과 우울증상 이 관련되는 이유를 유추해보면, 청소년기는 또래관계 및 타 인과의 관계성에 대한 욕구가 증가하는 시기로써 특히 또래와 의 친밀한 관계와 지지가 중요한데, 이러한 관계는 학교생활 적응뿐만 아니라 청소년의 삶의 전반에 중요한 영향을 미치는 요인이 될 수 있다(Choi \& Kim, 2015). 또한 우울은 의존적 우 울과 자기비판적 우울의 두 가지 유형으로 나뉠 수 있는데, 의 존적 우울은 타인으로부터 버림받는 것에 대한 두려움, 자신 에 대한 무력감, 보호와 애정을 원하는 소망을 일컫는다(Blatt, 1974). 이에 청소년의 관계성의 욕구의 좌절은 타인으로부터 버림받는 것에 대한 두려움을 일으켜 의존적 우울증상을 유발 할 수 있음을 유추할 수 있다.

추가적으로 남녀에 따른 주요 변인간의 상관을 분석한 결 과, 중학생 전체를 대상으로 한 상관분석 결과와 유사한 결과 가 도출되었으나 어머니의 과보호와 우울증상과의 관계에서 성별에 따른 차이가 나타났다. 즉, 남자의 경우 어머니의 과보 호와 자녀의 우울증상 간의 유의한 정적상관이 나타났지만, 여자의 경우 상관이 유의하지 않았다. 이는 남자의 경우 부모 의 과보호와 방임적 양육행동 모두 우울에 유의한 영향을 미 쳤고, 여자의 경우에는 방임만이 우울에 유의한 영향력이 있 었다는 선행연구 결과와 일치한다(Do, 2008). 다른 선행연구 에서도 남자의 경우 과보호 하위요인 중 과잉기대, 과잉간섭, 밀착통제, 투사적 과보호, 자녀분리불안이 우울증상과 유의한 
정적 상관이 있었지만 여자의 경우 과보호의 모든 하위요인과 우울간 유의한 상관이 나타나지 않았다(J. Kim \& Oh, 2011). 이러한 선행연구를 통해 여자청소년은 남자청소년과 달리 과 보호보다 돌봄과 같은 다른 요인이 우울증상과 연관될 수 있 음을 파악할 수 있다. 이러한 원인을 살펴보면, 여자청소년의 경우 부모의 양육행동을 긍정적으로 지각하는 경향이 있으며 (Moon, 2004), 어머니의 과보호를 자신에 대한 관심이나 애정 으로 받아들일 가능성 때문으로 유추된다. 또한 남아에 비하여 여아를 더욱 보호하고 통제하고자 하는 전통적인 양육태도와 사회적 분위기로 인하여 여아가 부모의 과보호를 상대적으로 더 수용하여 우울증상으로 발전하지 않았을 가능성도 있다.

셋째, 전체 중학생을 대상으로 어머니의 과보호와 우울증 상의 관계에서 기본심리욕구 하위요인의 매개효과를 검증한 결과 어머니의 과보호와 우울증상의 관계에서 자율성과 관계 성이 매개효과를 나타냈다. 반면, 유능감은 상관분석 결과와 마찬가지로 유의한 매개효과가 나타나지 않았다. 이는 어머니 의 높은 과보호가 청소년의 낮은 자율성과 관계성을 통해 우 울증상에 영향을 미친다는 것을 의미한다. 이러한 경로가 나 타난 원인을 우선 자율성과 관련하여 탐색해보면, 청소년기는 부모의 의존방식을 벗어나 자신을 스스로 통제하고 선택하며 독립하는 단계이기 때문에 자율성 획득이 매우 중요한 과업 이다. 이렇듯 중요한 시기에 자녀를 대신하여 모든 문제를 해 결해주는 어머니의 과보호는 기본심리욕구 중에서도 자율성 을 저해하는 가장 부정적인 양육방식으로 자녀로 하여금 행동 의 주체가 자신이 아니라고 느끼게 하여 수동적으로만 행동하 게 만들고 무기력감을 느끼게 하여 우울 등의 병리적인 증상 을 가질 가능성을 높일 것으로 유추된다. 어머니의 과보호와 우울증상의 관계에서 관계성도 매개효과를 나타냈는데, 이는 이러한 결과는 어머니의 높은 과보호가 청소년의 관계성 욕구 를 좌절시켜 우울증상을 높일 수 있음을 의미한다. 이러한 결 과는 자녀의 자율성을 지지하는 부모의 양육태도가 자녀의 관 계성을 매개하여 우울증상 완화에 영향을 준다고 밝힌 연구결 과(Inguglia et al., 2016)와 유사한 맥락이다. 특히 이 두 가지의 간접 경로 중 자율성을 매개변인으로 설정한 간접경로계수가 관계성을 매개변인으로 설정한 간접경로계수보다 유의미하 게 큰 것으로 확인되어, 어머니의 과보호가 우울증상에 미치 는 영향에서 중학생 자녀의 자율성의 중요성이 추가적으로 제 기되었다.

이에 본 연구는 어머니의 과보호와 중학생 자녀의 우울증 상의 관계에서 기본심리욕구 세 변인들의 역할을 개별적으로 탐색함으로써 어머니의 과보호가 어떤 경로를 통해 중학생 자
녀의 우울증상에 영향을 미치는지에 대한 매커니즘을 구체적 으로 규명하였다는 데 의의가 있다. 이는 청소년의 우울증상 을 더욱 효과적으로 완화 혹은 예방시키기 위해서는 어머니의 과보호적 양육태도를 감소시키는 것에 더해 청소년의 자율성 및 관계성을 충족시키는 개입을 통합적으로 시도하는 것이 적 합하다는 것을 시사한다.

넷째, 어머니의 과보호와 중학생 자녀의 우울증상과의 관계 에서 성별에 따른 기본심리욕구 세 하위요인의 매개효과를 검 증한 결과, 남녀 중학생 모두에게서 자율성이 유의한 매개효 과를 나타냈다. 즉, 높은 어머니의 과보호적 경향은 남녀중학 생 모두의 자율성을 저해시킴으로써 우울증상에 영향을 미친 다는 것을 의미한다. 반면, 관계성의 경우 여자에게서만 유의 한 매개효과가 나타났다. 이러한 경로의 차이가 나타난 원인 을 탐색해 보면 다음과 같다. 이는 여성이 더 관계지향적이며 대인간 유대 지향적인 경향이 강하기 때문에(Rose \& Rudolph, 2006) 여자 청소년의 경우 친밀한 의사소통과 정서적 신뢰를 중요시하고 관계지향 및 사회화가 더욱 강조됨을 유추할 수 있다. 더욱이 어머니의 과보호는 부모자녀관계에서의 갈등을 일으키고 관계지향적인 여자청소년에게 그러한 갈등은 자율 성 욕구 뿐 아니라 관계성 욕구를 더욱 좌절시켜 우울증상을 유발할 것으로 유추된다. 반면에 남자 청소년은 이러한 사회 화 과정이 덜 강조되기 때문에(Ryan, La Guardia, Solky-Butzel, Chirkov, \& Kim, 2005) 대인관계에 대한 부정적인 영향이 덜 할 뿐 아니라 어머니와의 양육적인 갈등이 관계적인 갈등으로 이 어지기보다 남자 청소년 자녀의 자율성 욕구좌절로 이어지게 하는 것으로 유추된다. 특히 남자 중학생의 경우 어머니의 행 동통제나 심리적 통제에 대해서 여자 청소년보다 부정적으로 인식함에 따라(Reeve \& Jang, 2006) 부모의 일방적인 지시나 강 요적인 태도가 부모와 갈등을 일으킬 가능성을 높이는 동시에 주체성과 통제감을 가질 수 없게 하여 자율성을 더욱 침해하는 것으로 유추된다. 이러한 결과는 어머니의 과보호로 인해 발생 된 청소년의 우울증상을 완화시키기 위해서는 남자 청소년의 경우 자율성에 초점을 두고, 여자의 경우 자율성과 관계성에 초점을 두고 개입해야 할 필요성을 시사한다.

이상의 논의를 종합해보면, 본 연구는 어머니의 과보호가 중학생 자녀의 우울증상에 미치는 영향에서 기본심리욕구의 매개효과를 검증하였다. 중학생 전체를 대상으로 매개효과를 분석한 결과 어머니의 과보호가 우울증상에 미치는 영향에서 자율성과 관계성이 매개효과를 나타냈다. 또한 남녀중학생 성 별에 따른 기본심리욕구의 매개효과를 분석한 결과, 남녀중학 생 모두 어머니의 과보호와 우울증상과의 관계에서 자율성이 
매개효과를 나타냈고, 여자중학생의 경우 관계성이 추가적으 로 매개효과를 나타냈다.

이에 본 연구는 어머니의 과보호가 중학생 자녀의 우울증 상에 영향을 미치는 경로에서 사회환경적인 영향인 어머니의 과보호가 개인내적 변인인 자녀의 기본심리욕구에 어떤 역할 을 하는지, 이로 인해 중학생 자녀의 우울증상에 어떤 영향을 주는지를 구체적으로 규명하였으며, 더 나아가 성별에 따라 이 경로의 양상이 어떤 차이를 나타내는지 탐색하였다는 데 의의가 있다. 이는 중학생 자녀의 우울증상을 설명하는데 있 어 기본심리욕구와 같은 개인내적 요인뿐 아니라 어머니의 과 보호라는 환경요인을 함께 고려해서 이해하고 개입해야한다 는 것을 시사한다. 특히 본 연구결과는 어머니의 과보호가 남 자중학생의 자율성과 우울증상에 부정적 영향을 미치는 것을 확인하였고, 여자중학생의 경우에는 자율성과 관계성에 부정 적 영향을 미쳐 우울증상을 유발한다는 것을 검증함으로써 어 머니의 과보호에 대한 부정적 영향을 탐색할 때 자녀의 성별 을 고려해야 할 필요성을 추가적으로 제기하였다.

본 연구의 제한점 및 후속연구를 위한 제언은 다음과 같다. 첫째, 본 연구에서는 어머니의 양육태도 중 과보호적 양육행 동만을 독립변인으로 설정하여 우울증상과의 관계에서 기본 심리욕구의 매개효과를 검증하였다. 하지만 어머니의 양육태 도에는 과보호적 양육태도 이외에도 돌봄, 방임, 심리적 통제 등의 다양한 양육태도가 있다. 또한, 본 연구는 어머니의 과보 호적 양육태도의 영향만을 탐색하였기 때문에 아버지의 과보 호적 양육태도나 다른 양육태도가 청소년의 기본심리욕구 및 우울증상에 어떠한 영향을 미치는지 검증하지 못하였다. 이에 다양한 부모의 양육태도가 청소년의 기본심리욕구와 우울증 상에 어떠한 영향을 미치는지를 후속연구를 통해 검증할 필요 가 있다.

둘째, 본 연구 결과 여자중학생의 경우 어머니의 과보호와 여자중학생의 우울증상간 유의한 상관이 나타나지 않았지만 기본심리욕구를 통한 매개모형은 유의하게 검증되었다. 이는 어머니의 과보호가 여자중학생의 우울증상에 직접적인 영향 을 주기 보다는 다른 변인의 영향을 통해 간접적으로 영향을 미치기 때문으로 유추되지만, 이에 대한 명확한 이유는 후속 연구를 통해 탐색될 필요가 있다. 이에 여자중학생의 경우 특 히 어머니의 과보호가 우울증상에 미치는 영향을 설명하는데 있어 다른 매개변인을 포함하여 검증할 필요성이 제기된다. 또한 남자중학생의 경우 모의 과보호와 우울증상과의 관계에 서 자율성만이 유의한 매개효과를 나타냈는데, 유능감, 관계 성의 경우 청소년의 연령, 학년 등의 어떤 다양한 요인으로 인
해 유의하지 않은 결과가 나타났는지에 대해 추가적인 탐색이 필요하다.

\section{Notes}

This article is a part of the first author's master's thesis submitted in 2017. We present a reanalysis of the original data in this article. This article was presented at the 2016 Annual Fall Conference of the Korean Association of Child Studies.

\section{Conflict of Interest}

No potential conflict of interest relevant to this article was reported.

\section{References}

\section{In English}

Abela, J. R., \& Hankin, B. L. (2008). Handbook of depression in children and adolescents: Causes, treatment, and prevention. In J. R. Z. Abela \& B. L. Hankin (Eds.), Handbook of depression in children and adolescents (pp.6-32). New York: The Guilford Press. doi:10.1017/S0033291708004480

Alloy, L. B., Abramson, L. Y., Tashman, N. A., Berrebbi, D. S., Hogan, M. E., Whitehouse, W. G., . . Morocco, A. (2001). Developmental origins of cognitive vulnerability to depression: Parenting, cognitive, and inferential feedback styles of the parents of individuals at high and low cognitive risk for depression. Cognitive Therapy and Research, 25(4), 397-423. doi:10.1023/A:1005534503148

Blatt, S. J. (1974). Levels of object representation in anaclitic and introjective depression. The Psychoanalytic Study of the Child, 29(1), 107-157. Retrieved from http://www.tandfonline. com/doi/abs/10.1080/00797308.1974.11822616

Centers for Disease Control and Prevention. (2015). 11th youth health behavior online survey statistics 2015. Retrieved from centers for disease control and prevention website: http:// yhs.cdc.go.kr.

Deci, E. L., La Guardia, J. G., Moller, A. C., Scheiner, M. J., \& Ryan, R. M. (2006). On the benefits of giving as well as receiving autonomy support: Mutuality in close friendships. Personality and Social Psychology Bulletin, 32(3), 313-327. doi:10.1177/0146167205282148

Deci, E. L., \& Ryan, R. M. (1985). Intrinsic motivation and self- 
determination in human behavior. New York: Plennum.

Eccles, J. S., Midgley, C., Wigfield, A., Buchanan, C. M., Reuman, D., Flanagan, C., \& MacIver, D. (1993). Development during adolescence: The impact of stage-environment fit on young adolescents' experiences in schools and in families. American Psychologist, 48(2), 90-101. doi:10.1037/0003066X.48.2.90

Hauenstein, E. J. (2003). Depression in adolescence. Journal of Obstetric Gynecologic and Neonatal Nursing, 32(2), 239-48. doi:10.1177/0884217503252133

Hayes, A. F. (2013). Introduction to mediation, moderation, and conditional process analysis: A regression-based approach. New York: Guilford Press.

Herbert, G. L., McCormack, V., \& Callahan, J. L. (2010). An investigation of the object relations theory of depression. Psychoanalytic Psychology, 27(2), 219-234. doi:10.1037/ a0019423

Holmbeck, G. N., Johnson, S. Z., Wills, K. E., McKernon, W., Rose, B., Erklin, S., \& Kemper, T. (2002). Observed and perceived parental overprotection in relation to psychological adjustment in preadolescents with a physical disability: The mediational role of behavioral autonomy. Journal of Consulting and Clinical Psychology, 70(1), 96-110. doi:10.1037/0022-006X.70.1.96

Inguglia, C., Ingoglia, S., Liga, F., Coco, A. L., Cricchio, M. G. L., Musso, P., ... Lim, H. J. (2016). Parenting dimensions and internalizing difficulties in italian and US emerging adults: The intervening role of autonomy and relatedness. Journal of Child and Family Studies, 25(2), 419-431. doi:10.1007/ s10826-015-0228-1

Joussemet, M., Landry, R., \& Koestner, R. (2008). A selfdetermination theory perspective on parenting. Canadian Psychology/Psychologie Canadienne, 49(3), 194-200. doi:10.1037/a0012754

Kovacs, M. (1996). Presentation and course of major depressive disorder during childhood and later years of the life span. Journal of the American Academy of Child \& Adolescent Psychiatry, 35(6), 705-715. doi:10.1097/00004583199606000-00010

Nolen-Hoeksema, S., \& Davis, C. G. (1999). "Thanks for sharing that": Ruminators and their social support networks. Journal of Personality and Social Psychology, 77(4), 801-814. doi:10.1037/0022-3514.77.4.801

Parker, G., Tupling, H., \& Brown, L. B. (1979). A parental bonding instrument. Psychology and Psychotherapy: Theory, Research, and Practice, 52(1), 1-10. doi:10.1111/j.20448341.1979.tb02487.x

Reeve, J., \& Jang, H. (2006). What teachers say and do to support student's autonomy during a learning activity. Journal of Educational Psychology, 98(1), 209-218. doi:10.1037/0022-
0663.98.1.209

Rose, A. J., \& Rudolph, K. D. (2006). A review of sex differences in peer relationship processes: Potential tradeoffs for the emotional and behavioral development of girls and boys. Psychological Bulletin, 132(1), 98-131. doi:10.1037/00332909.132.1.98

Ryan, R. M., La Guardia, J. G., Solky-Butzel, J., Chirkov, V., \& Kim, Y. (2005). On the interpersonal regulation of emotion emotional reliance across gender, relationships and cultures. Personal Relationships, 12(1), 145-163. doi:10.1111/j.13504126.2005.00106.x

Shrout, P. E., \& Bolger, N. (2002). Mediation in experimental and non experimental studies: New procedures and recommendations. Psychological Methods, 7(4), 422-445. doi:10.1037//1082-989X.7.4.422

Soenens, B., \& Vansteenkiste, M. (2005). Antecedents and outcomes of self determination in 3 life domains: The role of parents' and teachers' autonomy support. Journal of Youth and Adolescence, 34(6), 589-604. doi:10.1007/s10964-005-8948-y

Trouilloud, D., Sarrazin, P., Bressoux, P., \& Bois, J. (2006). Relation between teachers' early expectations and students' later perceived competence in physical education classes: Autonomy-supportive climate as a moderator. Journal of Educational Psychology, 98(1), 75-86. doi:10.1037/00220663.98.1.75

Veronneau, M. H., Koestner, R. F., \& Abela, J. R. Z. (2005). Intrinsic need satisfaction and well being in children and adolescents: An application of self determination theory. Journal of Social and Clinical Psychology, 24(2), 280-292. doi:10.1521/jscp.24.2.280.62277

Wexberg, E. (1974). Individual psychologie. Stuttgart: Hirzel.

Wickrama, K. A. S., Conger, R. D., \& Abraham, W. T. (2008). Early family adversity, youth depressive symptom trajectories, and young adult socioeconomic attainment: A latent trajectory class analysis. Advances in Life Course Research, 13, 161-192. doi:10.1016/S1040-2608(08)00007-5

\section{In Korean}

Ahn, H.-J., \& Mo, A.-R. (2012). A study on the relationship between the child's perceived mother's overprotection and the child's problematic behaviors by the child's enneagram personality type. Korean Journal of Family Welfare, 17(3), 125-148.

Cho, S. C., \& Lee, Y. S. (1990). Development of the Korean form of the Kovacs' Children's Depression Inventory. Journal of the Korean Neuropsychiatric Association, 29(4), 943-956. Retrieved from http://www.riss.kr/link?id=A1995886

Choi, J. E., \& Kim, M. J. (2015). The effect of family strength and peer support on middle school students' depression and anger. The Korean Journal of Applied Developmental 
Psychology, 4(2), 113-129. Retrieved from http://www. newnonmun.com/article $=10752293$

Chun, S. (2012). Mother's over-protectiveness and adolescent' anxiety: The effects of mediation on adolescent' autonomy. The Korean Journal of the Human Development, 19(4), 61-79. Retrieved from http://www.newnonmun.com/ article $=45340$

Chun, S., \& Han, Y. J. (2013). Mediating effect of higher perception on mother's overprotection and adolescent anxiety and aggression. Journal of Korean Coucil for Children \& Rights, 17(2), 285-308. Retrieved from http://www.newnonmun. $\mathrm{com} /$ article $=53478$

Chung, E. Y. (2008). Development of an overprotection scale and study for validity (Doctoral dissertation). Retrieved from http://www.riss.kr/link?id=T11431360

Chung, E. Y., \& Chang, S. S. (2008). The development of an overprotection scale based on teenagers' perception of their mothers. The Korean Journal of Counseling and Psychotherapy, 20(2), 293-312. Retrieved from http://www.dbpia.co.kr/ Journal/ArticleDetail/NODE06369657

Do, S. (2008). The influence of parents' discipline styles and dysfunctional parenting attitudes on emotional regulation and problem behaviors of adolescents: Focusing on gender difference (Master's thesis). Retrieved from http://www.riss. $\mathrm{kr} /$ link?id=T11559276

Ha, Y.-H. (2004). Effects of parent-adolescent relationships and depression on adolescents' problem behavior. The Korea Journal of Youth Counseling, 12(2), 42-52. Retrieved from http://www.riss.kr/link?id=A102573741

Jeong, H., \& Oh, I. (2016). A study on the effect of parentification and overprotectiveness on interpersonal problem: A focus on the mediation effect of emotional regulation style. The Korean Journal of Youth Counseling, 24(2), 259-277. Retrieved from http://www.riss.kr/link?id=A102574025

Jeoung, E.-G. (2007). The relationship between fathers and mothers parenting attitude and big-five personality of adolescents. Korean Journal of Youth Studies, 14(3), 79-110. Retrieved from http://www.dbpia.co.kr/Journal/ArticleDetail/ NODE06661279

Jung, H.-Y., Park, J.-H., \& Lee, S. I. (2004). The cognitive characteristics of somatizer according to depressive symptoms and sex. Journal of Korean Neuropsychiatric Association, 43(2), 165-171. Retrieved from http://www.riss.kr/ link?id=A18704692

Jung, J., \& Kim, J.-N. (2011). Gender differences in relationships between perceived parental behavior, cognitive emotion regulation strategies, behavioral inhibition and depression in early adolescents. Korean Journal of Youth Studies, 18(12), 227-254. Retrieved from http://www.dbpia.co.kr/Journal/ ArticleDetail/NODE06661826
Ki, M., \& Kim, M. (2014). The relationship between maternal overprotection, children's ego-resilience and school life adjustment: Focused on 4th, 5th and 6th graders of elementary school students. Journal of School Social Work, 29, 585-612. Retrieved from http://www.newnonmun.com/ article $=167696$

Kim, B. K., \& Min, B. B. (2006). The relationship among perceived parenting behaviors, temperament, character, and depression in adolescence. The Korean Journal of Clinical Psychology, 25(1), 221-236. Retrieved from http://www. dbpia.co.kr/Journal/ArticleDetail/NODE06371235

Kim, B. N., \& Choi, H. I. (2013). Effects of study over protective parent's raising attitude on university student's smartphone-addiction: The mediating effects of selfcontrol. Social Science Research Kyungsung University, 29(1), 1-25. Retrieved from http://www.dbpia.co.kr/Journal/ ArticleDetail/NODE06371235

Kim, C.-K. (2000). Individual psychological analysis on the influence of the parent's over-protection for the childrearing which affects the personality development of the child. The Journal of Play Therapy, 4(1), 35-49.

Kim, E. J. (2010). The relationship between perceived parenting behaviors and adolescent depression: Mediating effects of dysfunctional attitude and avoidance coping. Korean Journal of Clinical Psychology, 29(2), 407-425. Retrieved from http://www.dbpia.co.kr/Journal/ArticleDetail/ NODE06371494

Kim, H. Y. (2000). A study of the influences of parenting behavior perceived by the early youth on their psychosocial maladaptation (Doctoral dissertation). Retrieved from http://www.riss.kr/link?id=T10397921

Kim, J., \& Oh, K. J. (2011). The effect of parental overprotection on depression: The mediation effect of ego-resilience according to gender. The Korean Journal of Clinical Psychology, 30(3), 647-661. Retrieved from http://www. dbpia.co.kr/Journal/ArticleDetail/NODE06371571

Kim, S., \& Chung, O. (2011). Maternal overprotection, child emotion regulation and peer relationships: The mediating role of emotion regulation in children. The Korean Journal of the Human Development, 18(3), 69-92. Retrieved from http://www.newnonmun.com/article=27358

Kim, S.-S. (2015). The structural relationship among basic psychological needs, life goals, psychological wellbeing, \& depression. The Korean Journal of Educational Psychology. 29(1), 1-25. doi:10.17286/KJEP.2015.29.1.01

Korean Neuropsychiatric Association. (Ed.). (1998). Singyeongjeongsingwahak. Seoul: Hanauihaksa.

Kwak, K.-J., \& Mun, E.-Y. (1993). The relationships of psychological characteristics and depression and antisocial behavior in early adolescence. 1993 Annual Conference 
of Korean Psychological Association (pp. 31-40). Seoul, Korea. Retrieved from http://www.dbpia.co.kr/Journal/ ArticleDetail/NODE06375623

Lee, H. (2013). The relationship between parental autonomy support and psychological control on the psychosocial adaptation: The mediating effects of children's self-regulation styles (Doctoral dissertation). Retrieved from http://www.riss.kr/ link?id=T13103740

Lee, H. Y., \& Ha, E. H. (2015). Effects of cognitive vulnerability and gender differences to persistence on adolescent depressive symptom: A six months longitudinal study. The Korean Journal of Woman Psychology, 20(2), 157179. Retrieved from http://www.dbpia.co.kr/Journal/ ArticleDetail/NODE06502422

Lee, M. H., \& Kim, A. Y. (2008). Development and construct validation of the basic psychological needs scale for Korean adolescents: Based on the self-determination theory. The Korean Journal of Social and Personality Psychology, 22(4), 157-174. Retrieved from http://www.dbpia.co.kr/Journal/ ArticleDetail/NODE06373311

Lee, S., \& Choi, J. M. (2006). Maternal overprotective behavior and their children's aggression, withdrawal and perceived competence. The Korean Journal of Community Living Science, 17(2), 69-79. Retrieved from http://www.dbpia. co.kr/Journal/ArticleDetail/NODE00770337

Ma, E.-A., \& Son, E.-J. (2014). Maternal psychological control and university students' depression: The mediating effect of autonomy need thwarting and socially prescribed perfectionism. Korean Journal of Counseling, 15(5), 20352051.

Moon, K.-J. (2004). The effect of discrepancy between adolescent autonomy need and parental allowance on depression and rulebreaking behavior: mediating effect of conflict with parents (Doctoral dissertation). Retrieved from http://www.riss.kr/ link?id=T9500673

Moon, K.-J., \& Oh, K. J. (2002). The relationship between perceived parental behaviors and early adolescents' depression and anxiety. The Korean Journal of Clinical Psychology, 21(1), 29-43. Retrieved from http://www.dbpia.co.kr/Journal/ ArticleDetail/NODE06370981

Oh, U. J. (1998). The effects of perceived parent-child relationship on depression (Master's thesis). Retrieved from http://www.riss. $\mathrm{kr} / \mathrm{link}$ ?id=T7124567

Park, A.-C. (1998). A note on the over-protection for childrearing in its developmental psychological aspects. The Korean Journal of the Human Development, 5(1), 53-73. Retrieved from http://www.newnonmun.com/article $=2665$

Park, M. S., \& Ha, E. H. (2011). The moderating effects of stress types in the relationships between adolescence's personality predispositions and depressive symptoms. Korean Journal of
Play Therapy, 14(3), 53-73.

Ro, K., \& Shim, H. (2004). Bullying and victimization with perception of parenting behaviors among elementary school children. Journal of Child Studies, 25(6), 241-257. Retrieved from http://www.riss.kr/link?id=A102954847

Seong, E. M., Oh, H. S., Chol, Y. M., \& Joo, J. H. (2013). Study on youth happiness community's index development and policy I (Research report 13-R11-2). Retrieved from National Youth Policy Institute website: http://lib.nypi.re.kr/ pdfs/2013/11-2.pdf

Shin, H.-K. (2000). The effect of negative affectivity, alexithymia, somato-sensory amplification, and somatic attribution on somatization: Test of a linear mediation model. Korean Journal of Clinical Psychology, 19(1), 17-32. Retrieved from http://www.riss.kr/link?id=A100628120

Sohn, S.-H., Noh, K.-S., Huh, M. Y., Jung, H.-O., Lee, S. H., \& Kim, S. (2001). A study of adolescent problem behaviors and parenting behaviors. Journal of Korean Neuropsychiatric Association, 40(4), 605-615. Retrieved from http://www. riss.kr/link?id=A3002385

Suh, H. N. (2011). A longitudinal study of adolescents'suicidal ideation: Focusing on the effect of stress and depression. Korean Journal of Psychology, 30(3), 629-646. Retrieved from http://www.riss.kr/link?id=A100631643

Suk, M., \& Oh, I. (2014). Relations of perceived parental overprotection, negative automatic thought and anger among middle school students. Secondary Education Research, 62(3), 491-511. Retrieved from http://www.riss. $\mathrm{kr} / \mathrm{link}$ ?id=A100110331

Yi, S.-M., \& Lee, S. (2009). A relation of covert narcissism to depression and self-efficacy of adolescents. The Journal of Play Therapy, 13(2), 15-28. Retrieved from http://www.riss. $\mathrm{kr} /$ link?id=A76541957

Yoon, S.-J., \& Kang, S.-H. (2011). The relationships of perceived attachment, social support and problem behavior of middle school students. Journal of Fishries and Marine Sciences Education, 23(4), 582-592. Retrieved from http://www.riss. $\mathrm{kr} /$ link?id=A60019022

\section{ORCID}

Mi Young Baek http://orcid.org/0000-0001-5256-4797

So Yean Lee http://orcid.org/0000-0002-1186-2576

Received February 27, 2017

Revision received April 30, 2017

Accepted May 10, 2017 